ARTICLE

Received 27 Nov 2015 | Accepted 3 Aug 2016 | Published 6 Sep 2016

\title{
Exploring the science-policy interface on climate change: The role of the IPCC in informing local decision-making in the UK
}

\author{
Candice Howarth ${ }^{1,2}$ and James Painter ${ }^{3}$
}

\begin{abstract}
Building on the Intergovernmental Panel on Climate Change's (IPCC) review of how to make its Assessment Reports (ARs) more accessible in the future, the research reported here assesses the extent to which the ARs are a useful tool through which scientific advice informs local decision-making on climate change in the United Kingdom. Results from interviews with local policy representatives and three workshops with UK academics, practitioners and local decision makers are presented. Drawing on these data, we outline three key recommendations made by participants on how the IPCC ARs can be better utilized as a form of scientific advice to inform local decision-making on climate change. First, to provide more succinct summaries of the reports paying close attention to the language, content, clarity, context and length of these summaries; second, to better target and frame the reports from a local perspective to maximize engagement with local stakeholders; and third, to work with local decision makers to better understand how scientific advice on climate change is being incorporated in local decision-making. By adopting these, the IPCC would facilitate local decision-making on climate change and provide a systematic review of how its reports are being used locally. We discuss implications of these recommendations and their relevance to the wider debate within and outside the IPCC as to the most effective way the IPCC can more effectively tailor its products to user needs without endangering the robustness of its scientific findings. This article is published as part of a collection on scientific advice to governments.
\end{abstract}

\footnotetext{
${ }^{1}$ Anglia Ruskin University, Cambridge, UK ${ }^{2}$ University of Surrey, Guildford, UK ${ }^{3}$ University of Oxford, Oxford, UK
} 


\section{The IPCC and decision-making}

he IPCC's Assessment Reports (ARs) are widely regarded as the most important and authoritative publications on a global scale that summarize the state of knowledge about climate science, its real and potential impacts, and the possibilities of mitigation. The Fifth Assessment Report (AR5) was no exception, consisting of three voluminous working group (WG) reports: WGI, The Physical Science Basis (IPCC, 2013a); WGII, Impacts, Adaptation and Vulnerability (IPCC, 2014a, b); and WGIII, Mitigation of Climate Change (IPCC, 2014c), and a Synthesis Report (SYR) released in November 2014 (IPCC, 2014d). In spite of the vast amount of evidence they assessed around these three WG themes, climate change remains a complex issue to communicate to non-expert audiences particularly where an information deficit model approach is adopted, whereby the science of climate change is communicated to decision-makers with the assumption that this will adequately inform decision-making processes (Rapley et al., 2014). This linear model where science (facts) speaks truth to power (values) is the dominant paradigm among many climate scientists and policymakers (Jasanoff and Wynne, 1998). A key limitation to this, as discussed by Dessai et al., is that decision makers' and policymakers' expectations and over-reliance on evidencebased policy cannot be fulfilled, particularly where large uncertainties are involved and where decision-making processes are highly context-dependent, in that "(...) more than one outcome is consistent with expectations" (Dessai et al., 2009: 67). Nonetheless, there are clear benefits of scientific tools such as the IPCC ARs in aiding decision-making, but the "predict and provide" approach to science in support of climate change adaptation, for example, is "seriously flawed" (Dessai et al., 2009: 74). Policy-making is seen as a complex problem solving activity where "decision-makers [are] assumed to search for the best action among several alternatives" (Brunsson, 2007: 14). Consequently uncertainty in decision-making stems from the range of alternatives available and the process of choosing between them (Brunsson, 2007) and hence it is challenging to "understand, influence, control and hold to account" (Cairney, 2015: 3) these complex decision-making processes. This is particularly relevant to scientists who may seek to influence this; however, epistemological limits to the production of climate evidence (for example, predictions and projections) should not necessarily be interpreted as limits to related decisionmaking, particularly when large uncertainties in this evidence are concerned.

Decision-making approaches are dependent on context, and particularly a decision-maker's [in] ability to deal with abundant and complex information (lacking capacity or competence to do so) combined with the randomness of interactions between decision makers, solutions and alternatives. This means that decision-making "may not follow the norms of rationality" (Brunsson, 2007: 14). Similarly, adopting a pure information deficit approach where knowledge sharing and information provision are assumed to lead to action and robust evidencebased decision-making, can bring a set of challenges even when the political will exists. This results in "archetypal problems of decision-makers not getting information that they need and scientists producing information that is not used" (Cash et al., 2002: 1) and can lead to hypocritical decision-making processes less fruitful in delivering action where "decisions may relieve people of the burden of acting, and that decisions may obstruct action" (Brunsson, 2002: 176).

Research into the boundaries of the science-policy interface enables a deeper understanding of how to manage the challenges around communication and collaboration that arise from science-policy interactions (Jasanoff, 1990). Cash et al. (2002) suggest that evidence used to inform decision-making requires three key interconnected attributes: credibility (of the information produced through peer review and of those producing and reviewing it), salience (relevance of the information produced to decision makers), and legitimacy (the extent to which the information produced is fair and considered the values and needs of different actors). While much emphasis is placed on credibility in the IPCC process and a growing emphasis on legitimacy, we argue that salience, particularly in the context of local decision-making, is lacking. Indeed the IPCC has come under increasing scrutiny in recent years by scientific and political communities seeking to assess its future role. Despite the considerable amount of intellectual effort invested by hundreds of climate scientists in the ARs and the robust peer review process carried out to assess academic evidence, recent scrutiny of the IPCC's activities has highlighted some key challenges in maintaining Cash's credibility, salience and legitimacy attributes. In late 2009, the illegal hacking of emails from climate scientists at the University of East Anglia, UK and the media attention to a small number of errors in the AR4 reports prompted the UN and the IPCC to commission a report by the InterAcademy Council (IAC) of its reviews and processes. The results of the IAC urged the IPCC to adapt to the changing contexts to "continue to serve society well in the future" (IAC, 2010: xii) through a set of recommendations on its governance and management, its review process, communication and transparency in its assessment process; this speaks directly to Cash's credibility and salience attributes. A similar enquiry in the United Kingdom led by the House of Commons Energy and Climate Change Committee in 2014 concluded that "the [IPCC] would benefit from increasing the level of transparency by recruiting a small team of non climate scientists to serve the review process from start to finish", thus speaking to Cash's credibility and legitimacy attributes. Ultimately the Committee concluded that "there is no scientific basis for downgrading the UK's ambition to reduce greenhouse gas emissions" (House of Commons Energy and Climate Change Committee, 2014: 3). In February 2015 at a meeting held in Nairobi, the IPCC assessed submissions on how it could review its future work, in particular related to the frequency and scheduling of reports, the structure and operations of the IPCC (notably to increase the number of members from developing countries in the IPCC Bureau from 31 to 34), making reports more user friendly, making the Summary for Policy Makers (SPMs) more useful, and enhancing the role of developing countries (IPCC, 2015). This built on previous feedback provided by the political community on how the IPCC could revise its processes to promote greater transparency and inclusivity in the authors and experts which participate in the WG outputs to ensure a more balanced contribution across gender, geography, experience. The outcomes from this meeting reflect Cash's arguments on the importance of credibility, salience and legitimacy in the IPCC process. The UK's Department for Energy and Climate Change (DECC) was one of many to make submissions to the Nairobi meeting, having already consulted its devolved administrations, relevant departments, UK-based review editors and Coordinating Lead authors (DECC, 2013). It suggested that the IPCC:

- Deal more effectively with the increasing complexity and volume of material that needed to be synthesized in its ARs, particularly looking at the challenges faced in different geographical regions and the need to meet the needs of different end users;

- Adopt a more flexible approach to communication and expand its product range, particularly considering options for utilization of social media; 
- Consider the requirements of its end users such as policymakers, decision-makings and end users in a timely manner (for example, consider the more frequent publication of reports and/or special reports);

- Consider revising its structure particularly in addressing the silo approach adopted by each of the WGs, and encouraging reports to be coordinated and written by multi-disciplinary teams (for example, across WGs).

\section{Communicating the IPCC's findings for effective local decision-making}

On the specific issue of the communication of the reports, two key recommendations were made at the Nairobi meeting that aimed to make the reports more user friendly and better align with the evolving tools available to disseminate IPCC outputs more effectively: (i) to ensure that up-to-date digital technology is used to share and disseminate information; (ii) that it seek advice from various specialists to make IPCC reports more readable (IPCC, 2015). The focus on communication was significant because questions have been frequently raised about the effectiveness of the IPCC's work in this area. Black (2015) has argued that the SPMs, which are the principal way scientists communicate the findings of the WGs to policymakers and nonexpert audiences, are ill-suited for these audiences, mainly because of the jargon-filled language used and the failure to distil the main conclusions into a two-page briefing "of the type that world leaders are used to receiving from their aides". Hickman (2015) has applauded the IPCC's recent communication strategy, yet encourages it to modernize and adopt a more engaging approach by embracing online platforms to respond faster to newly available evidence base. He argues that although the IPCC has operated Twitter and Facebook accounts for several years, neither provided "much in the way of reactive interaction with its audiences".

As discussed above, we do not advocate the use of an information deficit approach in communicating climate science. However, a case can be made that in many ways this is the approach adopted by which the IPCC produces its Working Group reports, which are then used by decision makers to inform their practices. This therefore warrants investigations into the nature of the information presented in the IPCC's outputs, the extent to which it is used and perceived as useful. The language adopted by the IPCC, and in particular how uncertainty is communicated by using different ranges for certainty and confidence levels, has been seen as unhelpful (Patt and Schrag, 2003; Budescu et al., 2009, 2014), which could be interpreted as limiting its salience and legitimacy as a tool according to the Cash attributes. Hollin and Pearce (2015) explored how effectively IPCC scientists addressed uncertainty when presenting the findings of the WGI report at the press conference in September 2013. They argued that the scientists fell into what they called the "IPCC's certainty trap", and inconsistencies led to confusion within the press conference and subsequent condemnation in the media. In exploring the readibility of the language used in the IPCC's outputs, Barkemeyer et al. (2015) found that the SPMs stand out for "very low readability scores" (where an equivalent to a $\mathrm{PhD}$ level of understanding of climate science is needed), which have remained fairly constant despite the IPCC's efforts to amend its communications policy. These results were found to contrast with changes over time in coverage of the IPCC in scientific and broadsheet newspapers, with coverage on more recent reports generally being easier to read. Investigations into the use of risk language and framing in the communication of the IPCC reports (Painter, 2014, 2015a) found that although risk is a term well understood by many in the practitioner community, it is not yet well portrayed in the IPCC reports or its media coverage leading to a disconnect between assessments of scientific knowledge and requirements for informing decision-making (Viner and Howarth, 2014).

The IPCC's current communication strategy goes back to 2012 and the IAC review, when it established that the primary target audiences of its communications efforts are governments and policymakers at all levels (IPCC, 2012). It also identified what it called "broader audiences", such as the UN, IPCC observer organizations, the scientific community, the education sector, non-governmental organizations (NGOs), the business sector and the wider public as secondary targets for their information. While this clearly speaks to Cash's salience in terms of ensuring the ARs are relevant to decision-makers, few studies have been published offering detailed qualitative research on how these sectors, and particularly policymakers, view and use the AR reports. Clearly, the category of "government and policymakers" includes a wide range of types of policymakers from negotiators within the UN process, politicians, civil servants, local decision makers and planners, to representatives of bilateral and multilateral agencies. Politicians have been consulted frequently, but other sectors have often been neglected; this is particularly true of end users at the local level.

This is an important omission because challenges arising for adopting and implementing international and national plans of action to tackle climate change have led to an increase in locally based initiatives often linked with and demonstrating co-benefits to environmental, economic and social policies (Bedsworth and Hanak, 2013). Responses to climate change in terms of both mitigation and adaptation occur at the local level with a growing range of climate mitigation and adaptation measures taken at the local authority level (IBRD/World Bank, 2010), playing an instrumental role in achieving national and EU 2030 energy and climate targets. In addition, local decision-makers have a deep understanding of the impacts of climate change locally, how local stakeholders, communities and structures respond and their role in driving solutions for effective low-carbon transformations (Vogel and Henstra, 2015). Yet these audiences are not being fully acknowledged in the definition of its end users by the IPCC, which does not capture their needs and values in informing their decision-making processes. Considering the importance of context and particular, policymakers' limited time and availability to consider different policy issues (Cairney, 2014), this raises questions about the limitations of the scientific and political debate on responses to climate change (Beck, 2010). Considering the importance of Cash's salience and legitimacy attributes in informing decision-making, and our assessment of the IPCC's over reliance on the information deficit model discussed above, it is therefore surprising that the local and regional stakeholders and those with local experience and expertise, are not more fully involved in the process.

Climate change as a phenomenon has been conceived of and articulated at the global level, predominantly through the IPCC reports. In the United Kingdom, this is reflected by the 2008 Climate Change Act that established a framework for reducing national greenhouse gas emissions by at last $80 \%$ in 2050 from 1990 levels, and local climate policy development enacted through National Indicators (NI) carbon emissions targets (DCLG, 2008). Evidence informing decision-making on climate change is therefore grounded in natural science reflecting a scientific consensus on carbon emissions data as opposed to local policy responses to this evidence. Pearce (2014) examines the translation of scientific evidence into climate policy-making at the local level through the NIs concluding that in this instance, the science-policy process "excluded local knowledge about both the contexts for [emissions] and the ability of local 
authorities to exercise control over the sources of such emissions" (198). Local-scale data is sought by scientist to increase the accuracy of their global models. Similarly scientists are increasingly investigating local impacts of climate change in response to decision maker needs, who themselves are becoming more interested in the transferability and scalability of adaptation and mitigation activities (Cash and Moser, 2000). In considering how to design policy responses to climate adaptation, "upscaling" through the use of local case study analysis, for example, is increasingly seen as a useful evidence-base to develop public policy solutions grounded in contextual research (Larsen et al., 2012). Local policymakers are on the "front line" of local implementation of climate change solutions and therefore contribute to developing locally-based nationally impactful solutions to climate change (Argyriou et al., 2012). They rely on certain types of data such as rainfall, temperature and sea level rise to inform decision-making on issues ranging from energy efficiency, economic development and community well-being and growth, making them important climate change information users and obvious audiences of the IPCC reports (Argyriou et al., 2012). Nonetheless, research into local decision-making on climate change is scarce and requires an "unpacking of the different types of evidence used to inform policy $<$ which $>$ should be at the heart of attempts to evaluate policy success" (Pearce, 2014: 199)

It has been suggested that the IPCC could do more to be more useful to end-users and enable more actionable decision-making on the issue (Howarth et al., under review); climate scientists could engage more with the local environment within which they reside and work to increase engagement and understanding of the local dimensions of climate change (Howarth and Black, 2015), and to help shape better responses to climate risks and impacts at the local level (Kettle et al., 2014). In practical terms, decisionmakers across different sectors, who rely on climate-related data and information such as climate forecasts, often find the information they are provided to be complex, difficult to understand and requiring a level of translation to ensure suitability to both expert and non-expert users (Dessai et al., 2009). In addition, when considering Cash's credibility, salience and legitimacy attributes to ensure evidence can be effectively used to inform decision-making, the IPCC falls short in considering the relevance of WGII ARs (salience) and the extent to which these sufficiently consider the needs and values of local decision makers (legitimacy). In order to increase the use of relevant and useful information on climate change to inform decision-making around responses to climate impacts and risks, a better alignment is needed between what scientists perceive as useful evidence and what end-users consider to be usable (Lemos et al., 2012).

\section{Research methods}

We collected data from several interviews with local policy representatives in the East of England, UK, and three workshops with UK academics, practitioners and local decision makers.

Interviews. Seven local policy representatives from local councils and local government organizations in the East of England region in the United Kingdom (Cambridge, Essex, Norfolk and Suffolk) which is vulnerable to numerous impacts of climate change including sea level rise, were interviewed to provide a representation of the different types of roles that exist at the local policy level: councillors, climate change officers, developers of local climate change and environment strategies and local government agencies. Preliminary findings from these interviews were presented and discussed at the IPCC's Expert Meeting on Communication held in Oslo in March 2016 (Painter, 2015b). These are identified in the text below as Local Policymaker (LP) 1, 2 and so on. Interviewees were approached based on their role in shaping climate change policy and decision-making, as well as their knowledge and use of the IPCC reports in informing their decisions. Interviewees' experience and knowledge of climate change varied with some new to the issue and others having experience in engaging with academic and science literature to inform their decision-making. We chose to focus on three key areas of questioning-the usefulness of the AR reports, their language and clarity, and recommendations for the future (Table 1).

Workshops. In order to explore in more detail some of the challenges outlined in this article, and to supplement interview findings, three workshops were conducted in London, United Kingdom. A total of 46 participants were recruited from three categories as defined in Howarth and Monasterolo (2016): (1) scientific/academic community, (2) practitioner community (involved in design and implementation of climate solutions on the ground, can be based in commercial organizations) and (3) decision-making communities (involved in formulating policies and decisions on climate issues). Participants were from a range of backgrounds, expertise and levels of seniority within their organizations to enable a fair and mixed representation of views of those involved in different types of climate-relevant decisionmaking processes at different levels and scales. These individuals were approached based on their knowledge and experience of decision-making on climate change and their use of the IPCC reports (Table 2) and were identified as authors in the climate adaptation literature and/or belonging to institutions conducting work on climate change. Participants therefore where in positions

\footnotetext{
Table 1 | Interview questions

\begin{tabular}{|c|c|}
\hline Theme & Question \\
\hline $\begin{array}{l}\text { Use and } \\
\text { usefulness }\end{array}$ & $\begin{array}{l}\text { - To what extent did you use the 2013/4 IPCC reports to inform your work? } \\
\text { - Which of the IPCC "products" were the most useful and relevant for your work (press release, SPM, FAQs, website, press } \\
\text { conference, fact sheets, or other products)? } \\
\text { - If you produced your own material based on the IPCC reports, in what ways did you rely on the IPCC material, and how much did } \\
\text { you have to change it? }\end{array}$ \\
\hline $\begin{array}{l}\text { Language and } \\
\text { clarity }\end{array}$ & $\begin{array}{l}\text { - Would you say that there was a clear dominant message or narrative from the IPCC reports? } \\
\text { - How highly did you rate the clarity of the key findings? } \\
\text { - How would you rate the language used in SPMs and other IPCC products for simplicity, clarity and accessibility? }\end{array}$ \\
\hline
\end{tabular}
}




\begin{tabular}{|lccc|}
\hline Table 2 | Workshop participants & & \\
& Academic & Practitioner & Policy \\
\hline Workshop 1 & 3 & 6 & 5 \\
Workshop 2 & 5 & 7 & 3 \\
Workshop 3 & 7 & 6 & 4 \\
Total & 15 & 19 & 12 \\
\hline
\end{tabular}

\begin{tabular}{|ll}
\hline Table 3 | Focus group questions \\
Theme & Question \\
\hline IPCC Use & - How are the IPCC outputs used to inform decision- \\
& making? \\
& - What IPCC products do you use (SPM, press \\
& release, graphs etc) \\
& - What other resources do you use? \\
Practitioner & What is the role of practitioner-based evidence in \\
evidence & the IPCC process? \\
& $\begin{array}{l}\text { practitioner-based evidence in informing climate } \\
\text { decision-making? }\end{array}$ \\
Co-production & $\begin{array}{l}\text { Can a process of co-production facilitate this } \\
\text { process? }\end{array}$ \\
& $\begin{array}{l}\text { What are the key opportunities and challenges in } \\
\text { using practitioner evidence to inform climate } \\
\text { decision-making? }\end{array}$
\end{tabular}

that fit one of the aforementioned categories, and were approached via the project contacts and networks.

Participants were invited to one of three workshops (with some of the interviewees also participating in a workshop), on occasions where specific invitees were unable to attend, they were asked to send a substitute from their organization to represent them. Workshops were conducted over 3 days and addressed the following themes: IPCC use, practitioner evidence and the role of co-production (Table 3). This article reports on findings from the first theme.

Each focus group lasted half a day, adopted a semi-structured approach, with a structure piloted and assessed beforehand with participant and group discussions recorded with consent (Howarth and Monasterolo, 2016). The workshops where conducted under Chatham House rules to provide anonymity to participants and to encourage open constructive dialogue and sharing of information on the key themes discussed. Discussions were analysed using thematic analysis and preliminary results were produced as a workshop summary, which was shared with participants as part of an internal review and quality assurance process.

\section{Results}

From the large amount of data arising from the interviews and workshops, we focus on four elements that emerged from our analysis of the data, of which initial findings were discussed at the IPCC's Expert Meeting on Communication (Painter, 2015b): the general value and usage of the IPCC products; the language and clarity of the reports; their usefulness in helping local decisionmaking; and recommendations made by participants for the IPCC in the future.
The value and usage of IPCC products. It is clear that IPCC WG reports are considered by participants to be very authoritative, setting out the global evidence for climate change, but the vast amount of evidence presented by the ARs can be overwhelming. These reports are then translated by those involved in local decision-making processes to the local level for the design of locally-focused strategies, which are of particular relevance to towns and households. The SPMs and the SYR were the most commonly used by our interviewees; the IPCC websites and fact sheets (mainly on what the IPCC is) were consulted, but not widely. The SPMs in particular are used for background and to give support and justification for decisionmaking at the local level. In addition to the SPMs, press coverage and quotes from the WG reports were useful to highlight salient points, which add weight to the drivers of their policies. The succinct two-page summary in the SYR was particularly valued:

We are a public facing partnership and we run projects [on] domestic energy efficiency, business resource efficiency, [and addressing] community energy. (...) The detailed findings in WGI, II and III ... that's more information then we can actually use in our day to day work. The Synthesis report [was] the most useful because it just brings everything together. Its own easy to read and accessible summary [was] a hugely useful tool for us. (LP1)

The reports are also perceived to be a necessary and useful evidence base (for example, highlighting key data on sea level rise, temperature and rainfall) frequently used to provide background to local policy-making, such as climate change or environmental strategies and to assess alignment with national climate data from the UK Climate Impacts Programme (UKCIP).

'We keep abreast of the latest developments in the science and the IPCC reports we recognize completely as being the most authoritative source of information on the latest scientific findings.' (LP1)

In the workshop discussions, most of the participants stated that they predominantly used the WGI report on the science of climate change. However, they also used a range of IPCC outputs including other WG reports, the SPMs and press releases as a reference point to ensure their work and decision-making is wellgrounded in academic rigour and in line with current scientific thinking.

The IPCC is useful to anchor research. If you cite the IPCC, you pass the sniff test and your work will be considered credible. (Workshop 2)

The frequent use of WGI is in part due to what the IPCC represents: an international body created to assess the science of climate change and provide rigorous and balanced scientific information to decision makers because of its scientific and intergovernmental nature (as outlined by the IPCC itself: IPCC, $2013 \mathrm{~b}$ ). The quality of the science, as perceived by participants, is assured through its review process whereby hundreds of expert scientists who are chosen through a defined process volunteer their time to write the assessments as Coordinating Lead Authors and Lead Authors. The reports' peer review process also is highly regarded with recognition of the enormous task involving multiple rounds of drafting and review. As a result the IPCC has built a reputation-or a "brand" (Workshop 2) as some participants described it-for ensuring their outputs are comprehensive and objective. 
There was consensus across each of the workshops that the IPCC provides an invaluable repository of evidence on climate change, synthesizing the global research base on the science of climate change, its impacts and mitigation responses. As a result it provides a unique resource, which forms the basis for informing decision-making and a synthesis of the body of literature that exists on the issue which organizations, practitioners, individuals may not otherwise have access to. In this regard, the IPCC without a doubt is considered by those using their reports at a local level, as an invaluable source of evidence in large part due to its internationally recognized peer review process by international experts (Cash's credibility attribute). This reflects positively on the IPCC's alignment with the needs of its end users by providing a variety of outputs to facilitate the dissemination of its outputs (Cash's salience attribute) thereby to some extent blurring the boundaries of what specifically defines the extent and limitations of an information deficit approach to communicating climate evidence.

Language, accessibility and clarity. Generally, IPCC reports were rated highly by local policymakers in terms of clarity. They are considered to provide clear, dominant messages and headline findings on the evidence of climate change, impacts and human agency, which helped them when thinking about local policy. However, some pointed to the difficulties of the language in the IPCC reports that at times was perceived as inaccessible, heavy and dense.

It's very useful in the clear sort of headline findings but then I think a lot of the detail of the report is sometimes couched in quite technical language; (...) paraphrasing or explaining to a less informed audience was part of my role in the council. (LP6).

The difficult language in the reports was accepted as being a reflection of the evidence-base covered and the wide variety of target audiences other than local decision-makers, who are more likely to engage with local businesses, community groups, stakeholders, and internal staff on issues such as domestic energy efficiency. Many of those interviewed saw it as their role to translate the content to make it more accessible to internal staff who were unlikely to consult the reports themselves. There was general agreement that the IPCC would need to consider this carefully in the future if it is to consider the needs of its breadth of end users and remain relevant to decision-making at the local level (Cash's legitimacy and salience attributes).

If these reports are going to outreach to the main stream audience, then they really do need to come with much plainer language. (LP1)

Some of the things are quite general and then others relate to specific scenarios that are quite difficult to unpack, so I suppose the official answer is yes, I do find myself either interpreting or explaining a lot of the messages in the report rather than quoting directly. [It] would be more helpful to me trying to communicate to councils, schools, or average members of the public in Cambridge, if those things were expressed in slightly more layman's terms. (LP6)

We didn't change any of the findings but perhaps the wording sometimes. I know that the wording is designed to be as accessible as possible within the context that it's released but we still find that we sometimes have to put things in slightly plainer language without changing any of the essential messages. We're not attempting to interpret it. We are presenting it because of what it is, and where it's come from, but then sometimes, the language just needs to be softened a little bit. (LP1)

Interviewees found it difficult to follow the details of the full WG reports as these were considered to be less accessible; as a result, they expected that the reports are not widely read. Several said that if the aim is to reach a wider audience, then the reports need to be much clearer. For example, the Suffolk County Council Climate Change Partnership engages with different audiences on impacts at a local level and what people can do, and in that (local) context, the IPCC reports are not perceived as useful for that audience and purpose in mind. Interviewees said that this was when internal briefings and translation of the reports became necessary. However, it is important to note that in general, interviewees have seen an improvement in the language in the IPCC reports, particularly around more certainty of anthropogenic change, impacts and managing uncertainty around future changes.

Part of the reason I had to change languages was because of the [local] scale of my audience as opposed to the audience of the IPCC. The Environment Agency is very England centric, and also very focused on only certain impacts. (LP3)

While the choice of products available to end users is favoured, the manner in which the IPCC communicates its outputs was found by workshop participants to limit their use. Participants who use the IPCC outputs stated that they predominantly used quotes, headlines, graphs and the presentation slides available. This was true for academics and some practitioners who particularly praised the range of outputs available for AR5, including the websites, press releases, Twitter feed and so forth. However, the complicated nature of the data presented in the reports at times (for example, the terminology used and the formats), were difficult to use for every day purposes, in particular for local decision makers. Workshop participants stated they found the headline findings very useful, but some details of the reports (such as detailed scenarios) can be in technical language that is not always suitable for their audience (councillors, businesses, voluntary and community organizations, or the public) and requires a level of translation and detailed explanation. This led in some cases to other organizations being used as "knowledge brokers" (Workshop 3) to translate the information into a more understandable and useful format, such as the sector-specific reports published by the Cambridge University Institute for Sustainability Leadership (see CISL, 2014).

It was also acknowledged that most of the interviewees who engage with the IPCC reports are used to reading scientific reports about climate change; they felt that non-expert audiences would be unable to comprehend the content as readily. It was considered very useful to have snapshots of examples of impacts (such as temperature and rainfall), which were seen as very accessible but there was some confusion around scientific terminology, with slight discomfort expressed by some around communicating terms such as "very likely"; percentage ranges and visualizations of data are deemed much easier to communicate.

In the summaries it feels less scientific. It feels more accessible, and it feels more directly related to people's lives; when we're dealing with ordinary residents of Suffolk, when we're dealing with Councilor representatives, then that's absolutely crucial. Whilst the science is obviously incredibly vigorous and well 
researched, it's quite dry and boring to be able to go into the detail of that with people. If you've got clear, concise statements that are easily accessible and understandable by the man in the street, and give a clear message that feels like it impacts on their day-to-day life, then they're useful in helping you make an argument about why you're doing something. (LP7)

Informing the local decision-making context. Some local councils chose to distil the reports, particularly the SYR by creating short locally-relevant summaries of each WG report to give a local flavour and context to the reports; they would then disseminate these through local engagement activities with the public, businesses and other stakeholders. They built on the summary documents (such as the SYR 2-page summary and WG headline messages) to produce their own materials for internal and external use. The key headline messages from the IPCC reports were often translated via the production of briefing notes, as well as webinars on each of the reports; with the latter proving very popular. However, as interviewees require data to inform their local decision-making, the IPCC reports are not perceived as being particularly useful in communicating the local impacts and dimension of climate change and consequently rarely directly inform decision-making.

Often the communication of the reports' headline messages by local decision-makers is aimed at two audiences: internal senior managers and staff, as well as external facing staff; for the Environment Agency for example, this is mainly through the Climate Ready programme (see Wright, 2013). For this, the IPCC reports are not the only resource used: a combination of IPCC reports and briefing materials provided by DECC and other organizations are used to address issues of language and accessibility, inform their briefing notes and enable a better framing in a UK context. Some interviewees would use previous internal resources such as other strategic documents based on previous IPCC ARs, or "taking things from other local councils" (LP4) to populate, inform and frame their own resources. However, the IPCC resources are used on a continuing basis, and not just around the launch of the reports. For example, other resources provided by the IPCC for AR4 published in 2007 have been used since publication and not necessarily around the launch, particularly visualizations such as graphs and images. Interviewees predict a similar gradual usage of similar products from AR5 over time.

[We have used] case study examples of work and the impact of severe weather on communities and businesses, (...) anecdotal evidence from business owners, land owners, farmers of how things have changed in their lifetime and why they've taken the action that they've taken. That's often really helpful. It's much less scientific than the IPCC information. (...) Lots of the arguments persuading people to do things differently aren't based on the science. It's much more of a gut reaction and very local economic argument. (LP7)

However, the use of the IPCC reports is dependent on local policy priorities, and in the past, interviewees have relied on the reports as part of the evidence base to support the delivery of the NI on climate change adaptation and mitigation (a UK central performance monitoring process on climate change, abolished in 2010), and still currently consult the IPCC reports (and particularly the SPMs) in mapping the effects of climate change locally. In developing their own materials they say they are very conscious of ensuring consistency and quality control by not altering facts and figures from the original reports as they are aware how easily these can be misconstrued.

(...) as an organisation, with the amount of changes that we've had to undergo, it's just really a matter of finding our own priorities again... And at the moment, climate change isn't necessarily one of those immediate elements that we'd necessarily focus on. (...) [in the past] we used to, through the national indicators when they were going quite a few years back now, obviously that formed a key part of the work we did, and that on both our climate change mitigation and adaptation. (LP2)

The WG reports have been used as a reference point for the development of the Environmental Strategy for Norwich City Council to provide a general picture about climate change. The WG reports and the SPMs were closely consulted, but only as a generic high level account of climate change. In terms of evidence, local authorities tend to draw on resources from other councils more than the IPCC reports, which are more often used to reinforce the importance of a measure or initiative the council is developing or to justify more investment. In this regard, the IPCC therefore fails to fully ensure Cash's legitimacy attribute as its products do not always align with the needs and values of its end users, in this case local decision-makers who resort to consulting a combination of alternative resources available to them. While this enables them to fill an evidence gap, this is specific to the United Kingdom. It raises the central question as to the extent to which other countries (for example, developing countries with limited national capacity to have access to alternative evidence on national and local impacts and responses to climate change) can adequately access robust evidence to inform their practices locally to respond to climate change impacts.

When I was part of the ERDF funding programme from Europe, one of the objectives included climate change, and [we used] the data from the report in the set-up of the programme. (...) It was maybe limited in terms of what it actually eventually provided. I used the IPCC stuff as a reference point (...). The projects that the programme might support needed to be justified in terms of what it would be delivering in its outcomes. Admittedly lots of it was context setting, but it was useful on that basis. (LP5)

The IPCC reports are not perceived as being particularly useful in communicating the local impacts and dimension of climate change and consequently rarely directly inform decision-making on that level. An emerging observation from each of interviewees is that, while it provides the baseline and helps frame the broader context and scale within which local policy-making may be shaped, it "doesn't tell us anything we didn't already know that's required to make those sorts of decisions" (LP7). The data and evidence (for example on temperature) are useful to inform local policies such as "housing and how housing and retrofitting energy efficiency with housing would be critical in projects going forward" (LP5) and so through its various products, provides an array of resources to refer to where needed.

I looked at reports from the IPCC in drafting the [council's climate change] strategy back in 2012 but at a high level really to set out in summary what the evidence was around how climate was changing globally. What I essentially tried to do was translate that to a regional and local setting and therefore the things that the council needed to do. It informed the strategy at a fairly high level but there were a lot of other things that I drew on. (LP6) 
The IPCC's summaries for policymakers are not designed to better communicate scientific findings, but a negotiated document to create/ensure co-ownership. However, when used to inform decision-making this is exactly how they are perceived and hence there is a misalignment between what the IPCC ARs aim to achieve and what end users expect them to deliver. The IPCC reports have been used to inform decision-making for example as an "introduction in the City Council environment strategy" (LP4); they are considered "a prompt for conversations around the subject" (LP1); and the main messages are "distilled for the sort of types of audiences that we engage with" (LP1). They are considered to be a valuable resource to "reinforce the importance of a certain measure that the city council is doing, or something that we think they should be doing. For example, if we want to argue that they should put more money into the environmental strategy, that's maybe when something like the IPCC report would come up" (LP4). They have been particularly useful in some cases when advocating for more action on the climate change agenda, particularly in a context where one particular party may be trying to encourage another to demonstrate more leadership. However, interviewees emphasized the importance of targeting the content of the IPCC to specific audiences and that in the case of local policymakers, if the content of the IPCC report did not align with the needs of the audiences, then they will not be used or will need to be translated.

My audience here is councillors, political leaders, directors and leaders of our sections, whose focus is upon client-based financial savings and their own day-to-day business. It's always difficult to come across with something such as climate change and how that actually affects their day-to-day business. (LP2)

Evidence of climate change impacts and vulnerability are especially useful for local planning, and as such, practitioners have a need for local, specific data. However, at present, the IPCC does not offer this granularity, focusing instead on the regional levels (for example, in WGII). The ARs and other IPCC outputs reflect a more general picture, limiting their usefulness for those implementing adaptation strategies at the local level. When asked about alternative resources to fill these gaps, practitioners at the workshops provided a wide range of examples, including UKCP09, the UKCIP, the UK National Adaptation Programme, World Bank Reports, UK climate adaptation sub-committee reports, UK Environment Agency's Climate Ready programme, Norwegian Meteorological reports, the UK Climate Change Risk Assessment and the New Climate Economy report. It therefore becomes apparent that the IPCC is not perceived as fully and practically relevant to inform decision-making on climate change at the local level in the United Kingdom, and that in fact it is one of many resources used. As highlighted by participants arguments based on their experiences of using the ARs and their role as local decision makers on climate change, Cash's legitimacy attribute, and consideration of the needs and values of its end users is not satisfied fully.

Recommendations. Throughout the workshop discussions and interviews, participants were invited to provide their own recommendations on how the IPCC outputs might be better utilized at the local level. Analysis of their responses identified three broad themes, drawing on the results highlighted in the sections above, which focused on (1) the length and language of the reports; (2) the provision of more of a local focus; and (3) increased engagement and end user consultations.

Length and language. The IPCC reports are seen as exceptionally valuable. However, interviewees expressed the need for more summary documents, ideally no more than two pages with information on specific impacts (for example, temperature, rainfall and sea level rise) to enable quick and accessible information to inform decision-making. For example, interviewees praised the SYR summary and recommend the IPCC continue down this route. Such short, two-page summaries with key statistics and facts (a summary of the summaries) would also be very useful as a basis for writing the local council's climate change strategy as it would save a lot of time and resources.

The fact that the Synthesis report came with those one or two pages... a two page summary of essential messages (...) that's absolutely critical. So that's the approach that I'd recommend (...) an easy reference for what the reports are. (LP1)

Another of the principal limitations observed about the IPCC reports was the inaccessibility of the language to non-expert audiences, which was a severe obstacle to practical decisionmaking at the local government level; the reports need to be more readable and accessible.

A double-sider that might have changes of rainfall, changes of temperature, [would be useful] because the summary notes that I've been in receipt of before are still 40 pages. That makes it quite hard to read. When you're in the position like mine, which is interested and has a lot of background in relation to climate change, but isn't the premise of my job, you need to have quick, accessible information that you can go to in between meetings. (LP5)

Shorter summaries of the reports that had the broad headline findings and supported by some key kind of statistics and facts that would be very useful to me in writing the council's climate change strategy... I suppose it is about how the information could be presented for generalist policy makers like me rather than specialists. (LP6)

Making it local. Interviewees and participants expressed the need for the reports to be broken down into specific messages each local authority can use to help inform their decision-making on local transformations to a low-carbon economy while acknowledging the limits of this should inadequate or insufficient resources be available (Porter et al., 2015; Heidrich et al., 2016). On occasion, the way in which the IPCC frames climate change as a global issue can lead it at times to be dismissed at the local level. Specific recommendations were made by some interviewees about the need for more evidence showcasing new impacts or innovative solutions that are not already being used locally, and the possibility of working with "local champions".

If you wanted to make it easier for local authorities for example, I really think it needs to be broken down a lot more into what specific messages local authorities can take from it. (LP4)

Having some sort of local champion who is championing that message with examples that mean something to people living in this locality is something that would really help me. [We need] a network of local champions, people of standing that are saying, "This international announcement, these reports, have relevance to us here in Suffolk because X, Y, and Z." That's something that would certainly bring more residents to the information locally. (LP7)

Engagement and end user consultations. Workshop participants and interviewees discussed how the IPCC could make its WGII 
reports more useful and effective in informing action to adapt to climate change by incorporating evidence from the local level, in addition to evidence from the national or international levels. In the workshops, there was considerable debate as to the extent to which the IPCC could or should make their reports more useful by incorporating more material on the local level, however, defined. Some participants maintained that it was not within the IPCC's remit to focus on the local level (even though local case studies are provided in some of the AR5 WGII outputs) and that instead the IPCC's role was to inform national decision-makers (Workshop 1). Several participants, particularly practitioners, also raised the issue that it would be costly and would become a "bureaucratic nightmare" (Workshop 1) if IPCC scientists were required to work with local decision makers and practitioners for gathering, organizing and synthesizing data into an IPCCapproved format.

However, other participants argued that adaptation itself is a context-specific issue, and several suggested that the IPCC could make its WGII reports more useful in informing action to adapt to climate change by incorporating local-level evidence. It was agreed that such evidence gathered from practitioners and local decision-makers for example would uniquely provide the IPCC and its scientists with evidence regarding best practice at the local level, giving concrete examples and case studies of good practice which traditionally the IPCC has been unable to do.

Practitioners are at the forefront of planning and implementing solutions therefore the case studies that arise from this are essential evidence of what works and what doesn't work at any scale (national, local, household, individual). (Workshop 2)

As discussed above, the gathering of evidence for the IPCC reports is an exercise conducted primarily by the scientific community, albeit with a small number of non-academics such as practitioners involved in the IPCC as authors. It scarcely takes into account needs articulated by decision makers working "on the ground". Current IPCC practice also allows practitioners to take part in the process, for example, as observers in sessions as long as they are "qualified in matters covered by the Intergovernmental Panel on Climate Change" (IPCC, 2012: 1). This is further reflected in the IPCC's new chair's intention to include more experts from developing countries and expertise from business and industry (Schiermeier and Tollefson, 2015). However, the IPCC does not explicitly consider the extent to which its findings will be accessible to or utilized by individuals and organizations involved in local decision-making on climate change (Howarth et al., under review). In addition, localized expertise, in the form of indigenous knowledge features scarcely in the IPCC reports (particularly WGII) challenging the extent to which the knowledge base assessed in the ARs is sufficiently inclusive of expertise and understanding of vulnerability, expertise, experiences and characterization of impacts and adaptation associated with climate change (Ford et al., 2012). As targets implemented through international and national policies will affect and require participation by ordinary citizens, their awareness, understanding, engagement and personal action is necessary to ensure uptake of measures and sustained changes to fill gaps where legislation and technology are insufficient to achieve success on their own (Barkemeyer et al., 2015).

\section{Conclusions}

This paper has presented fresh empirical material on local perceptions of the AR5 IPCC report, which makes an important addition to the body of evidence on climate-related sciencepolicy interactions. Evidence-based understanding of how different types of policymakers use the IPCC reports is thin on the ground in general, and particularly at the local level. This article clearly speaks to the current debate on the role of the IPCC in the future and in particular to some of the main areas of discussion and recommendations of the IPCC expert meeting on communication held in February 2016 in Norway, which included debates on the readability and clarity of its reports, the methods of reaching key decision makers at the national and regional level in different parts of the world, and the production of reports relevant to those sectors (http://ipcc.ch/meeting documentation/meeting_documentation_ipcc_workshops_and_ expert_meetings.shtml).

The results from this research have highlighted some clear gaps in informing decision-making at the local level, particularly in considering Cash et al.'s (2002) argument on the need for evidence to be credible, salient and legitimate to inform decisionmaking: findings from participant discussions highlight how the IPCC is perceived as credible, fairly salient yet limited in terms of salience at the local level (Table 4). Workshop and interview data with local decision makers, academics and practitioners have endorsed the undeniable value that the IPCC brings to informing the evidence base on climate change, providing a useful reference point. The WG reports, and particularly the SPMs and SYR, are seen as very authoritative, providing a stamp of approval and setting out the global evidence for climate change. The reports endorse the evidence base on climate change with clear, dominant messages facilitating thinking of the broader context within which local policy is designed and implemented. However, we acknowledge that there exist significant epistemological challenges to providing localized, tailored information at regional and local scales while retaining a high level of scientific credibility. For example, Frigg et al. (2015) urge caution on the over-reliance of model projections in informing decision-making, particularly where model outputs are subject to errors and uncertainties, as these may undermine ability to make robust decisions. In addition the requirement to provide tailored and localized information conflicts with other demands for increased salience, clarity, simplicity and user-friendliness in the IPCC's language. More research is therefore needed into mapping how the IPCC science feeds into the decision-making process at different levels and particularly to ensure it is considered as legitimate, providing information that is fair and considers the needs and values of its end users at the local level. In addition, the intricate and technical language used in the IPCC reports was identified as a key limitation to its use, being referred to as inaccessible, heavy and dense resulting in a need to paraphrase and translate the text into layman terms. While this was accepted as a result of the nature of the evidence assessed and reference in the reports, and generally it was felt that there had been a noticeable improvement in the language in the IPCC ARs over the years, this is perceived as a significant shortcoming when engaging with audiences such as local policymakers, local businesses, councils, schools, community groups, stakeholders, members of the public, and internal staff. Such observations by users also chime with some of the academic research described in the section "The IPCC and decisionmaking" above (Black (2015),Barkemeyer et al. (2015) and Dessai et al. (2009). The plea for clearer, more accessible language has been echoed by other key users of the IPCC reports and their target audiences, such as business sectors, NGOs, and the media (Painter, 2015b). Similarly, such audiences have agreed with the sentiments of the local policymakers interviewed here and recommended a two-page summary of the headline statement of each of the WG reports, along the lines of the one produced for WGI (Painter, Ibid.).

Another widespread theme emerging from both the interviews and workshops, aligning with Cash's legitimacy attribute, was that 


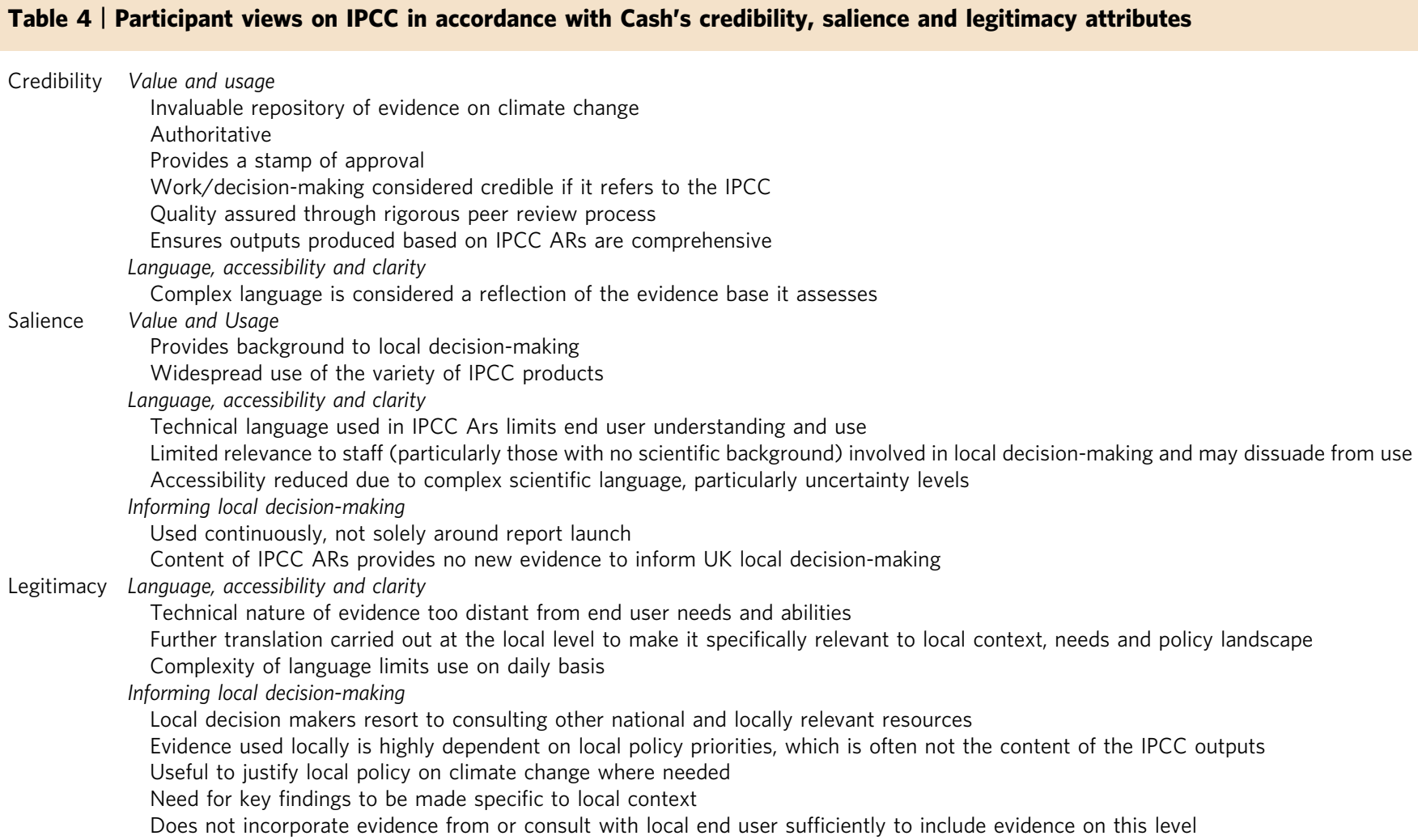

there was a pressing need for a locally led translation, production and dissemination of succinct summaries by its users to ensure better alignment and relevance to local priorities and end user needs. The IPCC outputs (and particularly the WGI report) are relied upon to help frame local environment and sustainability strategies. A number of engagement and dissemination activities to showcase the key findings from the IPCC reports tend to take place through local avenues, both to internal and external audiences, with the use of innovative and ICT-based methods such as webinars, seminars, case studies and printed summaries tailored to specific audiences and relevant to policy and economic priorities (such as energy efficiency, local flooding and so forth). However, a significant gap expressed by interviewees and participants is that, whilst WGI is used to help make the case for local action on climate change, WGII does not provide the data required to adequately inform local decision-making around responses to climate change, and hence alternative resources such as national data sets, are used to fill this gap. While it is recognized that it is not within the IPCC's remit to focus on the local level, climate change is a local and context-specific issue and it was felt by interviewees that the IPCC could reflect on the general principle of ensuring a two-way communication process by which it synthesizes evidence to inform local decision-making on climate change whilst simultaneously drawing on more localized expertise and producing evidence to help shape the content of its reports (notably WGII).

There are clearly some limitations and challenges to the recommendations emerging from our research, when the wider priorities and remit of the IPCC are taken into consideration. Currently, the IPCC reports are aimed mainly at national governments, national policymakers and national negotiators such as those present at the regular UNFCCC meetings. However, there is an appetite, and a need, to deepen the debate about priority target audiences in the future and about the availability of reports which are more useful at the national, regional and local level. Our research feeds into the debate how audiences other than national governments can benefit more from IPCC reports, or their views more taken into account in the scoping and writing of the reports, without compromising the IPCC mandate or the robustness of the IPCC science.

There are indeed underlying inequalities in the availability of different forms of information to decision makers around the world, so the important question arises as to why an intergovernmental body such as the IPCC should dedicate its scarce resources to the provision of localized information for UK decision makers at the expense of allocating these resources to other regions of the world lacking such expertise. We would argue that in the United Kingdom, it would be possible to create national or regional "Climate Service Centres" whose aim would be to translate scientific knowledge from various sources including the IPCC for local regional needs (although the question would remain as to how to fund them). This would enable a better alignment of the IPCC's processes and outputs with the needs of those working on the ground and provide a model for information translation, directly used to inform evidence-based decision-making on climate change locally, with scope to explore transferability to other contexts and geographies.

The evidence from this research also points to the wider issue of how to provide information more relevant to end users, either at the regional or sectoral level. Addressing the disconnection between producers of climate knowledge (and resulting outputs such as the IPCC) and its users as reflected in this article would clearly add an extra burden on IPCC authors and scientists to engage publicly with the issue. However, in general we believe that increased reflection and incorporation of different end user views and interests such as those of local decision makers is 
needed (Howarth, under review). Again, this recommendation coincides with other academic research already referenced in the section "The IPCC and decision-making" that speaks to the need for the IPCC to be more sensitive to what end users consider useful and useable as opposed to what the scientists may view as useful evidence (Lemos et al., 2012), and to the need to address the challenges of reconciling legitimacy, salience and credibility at different scales (Cash et al., 2002).

It also resonates with one of the recommendations from DECC in the United Kingdom for the IPCC to consider "the requirements of its end users in a timely manner" (DECC, 2013). The wider survey of IPCC target audiences mentioned above (Painter, 2015b) also strongly recommends that the IPCC should engage in more user consultation to gain more insight into how it might better tailor its products to user needs. Policymakers and other sectors like businesses said they would like more input for example, into the scoping of the reports to help ensure that policy concerns are flagged more clearly in the final reports, and that IPCC reports would better inform decision-making. This, they argued, would fit with a general approach to communications that is more interactive and engaging rather than top-down. In assessing the recommendation, however, we are aware that further research is needed to explore how the IPCC can incorporate such inputs from such expert groups and different policymakers into the scoping of future reports and their final publications.

In conclusion, the three recommendations made by participants and reported here reflect the needs of a core category of the IPCC's end users and speak to the wider debate in the public sphere about the priorities in next (6th Assessment) period of the IPCC under the new chair, Hoesung Lee Academics are not alone in arguing that the IPCC "must generate and incorporate knowledge about how information filters through society and about the kind of policies that are most likely to work" (Nature, 2015); sociologists, psychologists, anthropologists and political scientists must be an integral part of the next IPCC phase. To this list we would add policymakers at the local and regional level.

\section{References}

Argyriou I, Fleming P and Wright A (2012) Local climate policy: Lessons from a case study transfer of expertise from UK local authorities. Sustainable Cities and Society; 5 (5): 87-95.

Barkemeyer R, Dessai S, Monge-Sanz B, Gabriella Renzi B and Napolitano G (2015) Linguistic analysis of IPCC summaries for policymakers and associated coverage. Nature Climate Change; (6): 311-316.

Beck S (2010) Moving beyond the linear model of expertise? IPCC and the test of adaptation. Regional Environmental Change; 11 (2): 297-306.

Bedsworth LW and Hanak E (2013) Climate policy and the local level: Insights from California. Global Environmental Change; 23, 664-677.

Black R (2015) No more summaries for wonks. Nature Climate Change; 5 (4): $282-284$.

Brunsson N (2002) The Organization of Hypocrisy: Talk, Decisions, Action in Organizations, 2nd edn, Copenhagen Business School Press: Norway, p 242.

Brunsson N (2007) Consequences of Decision-Making. Oxford University Press: Oxford, GBR.

Budescu DD, Broomell S and Por H-H (2009) Improving communication of uncertainty in the reports of the intergovernmental panel on climate change. Psychological Science; 20 (3): 299-308.

Budescu DV, Por HH, Broomell S and Smithson M (2014) The interpretation of IPCC probabilistic statements around the world. Nature Climate Change; 4 (6): 508-512.

Cairney P (2014) How can policy theory have an impact on policy making? The role of theory-led academic-practitioner discussions. Teaching Public Administration; 33 (1): 22-39.
Cash DW and Moser SC (2000) Linking global and local scales: Designing dynamic assessment and management processes. Global Environmental Change; 10, 109-120.

Cash DW, Clark W, Alcock F, Dickson NM, Eckley N and Jaeger J (2002) Salience, Credibility, Legitimacy and Boundaries: Linking Research, Assessment and Decision-making. KSG Working Paper Series RWP02-046, Harvard University, USA.

Cairney P (2015) Debate: What is complex government and what can we do about it? Public Money and Management; 35 (1): 3-6.

CISL. (2014) IPCC climate science business briefings, http://www.cisl.cam.ac.uk/ business-action/low-carbon-transformation/ipcc-briefings/climate-science, accessed 13 November 2015.

DCLG. (2008) National Indicators for Local Authorities and Local Authority Partnerships: Handbook of Definitions. DCLG: London.

DECC. (2013) Future of the IPCC-UK government response to IPCC. Published 25 June, https://www.gov.uk/government/uploads/system/uploads/attachment data/file/210342/Future_of_IPCC_-_UK_response_25_June_2013.pdf. accessed 21 June 2015.

Dessai S, Hulme M, Lempert R, Pielke R Jr (2009) Climate prediction: A limit to adaptation? In: Adger NW, Lorenzoni I and o'Brien K (eds). Adapting to climate change: Thresholds, Values, Governance. Cambridge University Press: UK, p 515.

Ford JD, Vanderbilt W and Berrang-Ford L (2012) Authorship in IPCC AR5 and its implications for content: Climate change and Indigenous populations in WGII. Climatic Change; 113, 201-213.

Frigg R, Smith AA and Stainforth DA (2015) An assessment of the foundational assumptions in high-resolution climate projections: The case of UKCP09. Synthese; 192, 3979-4008.

Heidrich O et al (2016) National climate policies across Europe and their impacts on cities strategies. Journal of Environmental Management; 168, 36-45.

Hickman L (2015) The IPCC in the social media age. Nature Climate Change; 5 (4): 281.

Hollin GJS and Pearce W (2015) Tension between scientific certainty and meaning complicates communication of IPCC reports. Nature Climate Change; 5, 753-756.

House of Commons Energy and Climate Change Committee. (2014) Intergovernmental panel on climate change fifth assessment report: View of working group 1 contribution. London, the Stationery Office, http://www.publications.parliament.uk/pa/cm201415/cmselect/cmenergy/587/587.pdf, accessed 21 October 2015.

Howarth C (under review) Increasing public engagement on climate change in the UK: The role of co-production. Environmental Communication.

Howarth C and Monasterolo I (2016) Understanding barriers to decision making in the energy-food-water nexus: The added value of interdisciplinary approaches. Environmental Science \& Policy Journal; 61 (July): 53-60.

Howarth C and Black R (2015) Local science and media engagement on climate change. Nature Climate Change; 5 (6): 506-508.

Howarth C, Viner D, Dessai S, Rapley C and Jones A (under review) Co-producing climate assessments: Incorporating practitioner knowledge into the IPCC process. Submitted to Climate Services.

IBRD/World Bank. (2010) Cities and climate change: An urgent agenda. Urban Development Series Knowledge Papers, December, Vol 10, The World Bank: Washington DC.

InterAcademy Council. (2010) Climate change assessments: Review of the processes and procedures of the IPCC. Committee to review the Intergovernmental Panel on Climate Change, https://www.ipcc.ch/pdf/IAC_report/IAC\% 20Report.pdf.

IPCC. (2012) Decisions taken with respect to the review of IPCC processes and procedures: Communications Strategy. IPCC 35th Session, 6-9 June, Geneva. Available at https://www.ipcc.ch/meetings/session35/IAC_CommunicationStrat egy.pdf, accessed April 2016.

IPCC. (2013a) Climate Change 2013: The Physical Science Basis. Contribution of Working Group I to the Fifth Assessment Report of the Intergovernmental Panel on Climate Change [T.F. Stocker, D. Qin, G.-K. Plattner, M. Tignor, S.K. Allen, J. Boschung, A. Nauels, Y. Xia, V. Bex and P.M. Midgley (eds)]. Cambridge University Press, Cambridge, UK and New York, NY, 1535.

IPCC. (2013b) IPCC factsheet: what is the IPCC? August, https://www.ipcc.ch/ news_and_events/docs/factsheets/FS_what_ipcc.pdf, accessed April 2016.

IPCC. (2014a) Climate Change 2014: Impacts, Adaptation, and Vulnerability. Part A: Global and Sectoral Aspects. Contribution of Working Group II to the Fifth Assessment Report of the Intergovernmental Panel on Climate Change [ C.B. Field, V.R. Barros, D.J. Dokken, K.J. Mach, M.D. Mastrandrea, T.E. Bilir, M. Chatterjee, K.L. Ebi, Y.O. Estrada, R.C. Genova, B. Girma, E.S. Kissel, A.N. Levy, S. MacCracken, P.R. Mastrandrea, and L.L. White (eds)]. Cambridge University Press, Cambridge, UK and New York, NY, 1132. 
IPCC. (2014b) Climate Change 2014: Impacts, Adaptation, and Vulnerability. Part B: Regional Aspects. Contribution of Working Group II to the Fifth Assessment Report of the Intergovernmental Panel on Climate Change [V.R. Barros, C.B. Field, D.J. Dokken, M.D. Mastrandrea, K.J. Mach, T.E. Bilir, M. Chatterjee, K.L. Ebi, Y.O. Estrada, R.C. Genova, B. Girma, E.S. Kissel, A.N. Levy, S. MacCracken, P.R. Mastrandrea, and L.L. White (eds)]. Cambridge University Press, Cambridge, UK and New York, NY, 688.

IPCC. (2014c) Climate Change 2014: Mitigation of Climate Change. Contribution of Working Group III to the Fifth Assessment Report of the Intergovernmental Panel on Climate Change [O. Edenhofer, R. Pichs-Madruga, Y. Sokona, E. Farahani, S. Kadner, K. Seyboth, A. Adler, I. Baum, S. Brunner, P. Eickemeier, B. Kriemann, J. Savolainen, S. Schlömer, C. von Stechow, T. Zwickel and J.C. Minx (eds)]. Cambridge University Press, Cambridge, UK and New York, NY.

IPCC. (2014d) Climate Change 2014: Synthesis Report. Contribution of Working Groups I, II and III to the Fifth Assessment Report of the Intergovernmental Panel on Climate Change [Core Writing Team, Pachauri RK and Meyer LA (eds)]. IPCC, Geneva, Switzerland, 151.

IPCC. (2015) IPCC takes decisions on future work, IPCC secretariat, Geneva, Switzerland. 27 February.

Jasanoff S (1990) The Fifth Branch: Science Advisors as Policymakers. Harvard University Press: Cambridge, MA.

Jasanoff S, Wynne B (1998) Chapter 1: Science and decision making. In: Rayner S and Malone EL (eds). Human Choice and Climate Change. Batelle Press: Columbus, $\mathrm{OH}, \mathrm{pp} 1-87$.

Kettle NP, Dow K, Tuler S, Webler T, Whitehead J and Miller KM (2014) Integrating scientific and local knowledge to inform risk-based management approaches for climate adaptation. Climate Risk Management; 4-5, 17-31.

Larsen RK et al (2012) A framework for facilitating dialogue between policy planners and local climate change adaptation professional: Cases from Sweden, Canada and Indonesia. Environmental Science and Policy; 23, $12-23$.

Lemos MC, Kirchhoff CJ and Ramprasad V (2012) Narrowing the climate information usability gap. Nature Climate Change; 2, 789-794.

Nature. (2015) A shift in Climate. Editorial 526 (7573): 293.

Painter J (2014) Disaster Averted? Television Coverage of the 2013/14 IPCC's Climate Change Reports. RISJ: Oxford.

Painter J (2015a) Disaster, uncertainty, opportunity or risk? Key messages from the television coverage of the IPCC's 2013/4 reports. Metode Science Studies Journal; 6: 81-87.

Painter J (2015b) The effectiveness of the IPCC communication: A survey of (mainly) UK-based users. Paper submitted to the IPCC Expert Meeting on Communication, Oslo, February 2016, http://ipcc.ch/meeting_documentation/ pdf/Communication/JPI_study_REPORT_3_Sep_2015_JPainter.pdf, accessed May 2016.

Patt AG and Schrag DP (2003) Using specific language to describe risk and probability. Climate Change; 61, 17-30.

Pearce W (2014) Scientific data and its limits: Rethinking the use of evidence in local climate change policy. Evidence and Policy; 10 (2): 187-203.
Porter JJ, Demeritt D and Dessai S (2015) The right stuff? Informing adaptation to climate change in British local government. Global Environmental Change; 35 , 411-422.

Rapley C et al (2014) Time for a change? Climate Science Reconsidered. The Report of the UCL Policy Commission on Communicating Climate Science, University College London, UK.

Schiermeier Q and Tollefson J (2015) Four challenges facing newly elected climate chief; Nature (525).

Viner D and Howarth C (2014) Practitioners' work and evidence in IPCC reports. Nature Climate Change; 4, 848-849.

Vogel B and Henstra D (2015) Studying local climate adaptation: A heuristic research framework for comparative policy analysis. Global Environmental Change; 31, 110-120.

Wright J (2013) England's climate ready support service. Presentation at the 2013 European Climate Change Adaptation Conference, http://eccaconf.eu/presenta tions/PDF/ECCA2013-12b-5_7_1-Wright.pdf, accessed 13 November 2015.

\section{Data availability}

Data sharing not applicable to this article as no datasets were generated or analysed during the current study.

\section{Acknowledgements}

The research reported in this article was funded by the UK ESRC Centre for Climate Change Economics and Policy (CCCEP) Climate Policy Innovation Fund and the Joint Programming Initiative (JPI) Climate AR5 in Europe project. The authors would like to thank workshop participants and interviewees for their contributions to the discussions and Mott MacDonald for providing the venues to host the workshops. Additional thanks are extended to Anglia Ruskin University, Oxford University and the University of Surrey for supporting this research.

\section{Additional information}

Competing interests: The authors declare no competing financial interests.

Reprints and permission information is available at http://www.palgrave-journals.com/ pal/authors/rights_and_permissions.html

How to cite this article: Howarth C and Painter J (2016) Exploring the science-policy interface on climate change: the role of the IPCC in informing local decision-making in the UK. Palgrave Communications. 2:16058 doi: 10.1057/palcomms.2016.58.

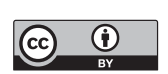

This work is licensed under a Creative Commons Attribution 4.0 International License. The images or other third party material in this article are included in the article's Creative Commons license, unless indicated otherwise in the credit line; if the material is not included under the Creative Commons license, users will need to obtain permission from the license holder to reproduce the material. To view a copy of this license, visit http://creativecommons.org/licenses/by/4.0/ 